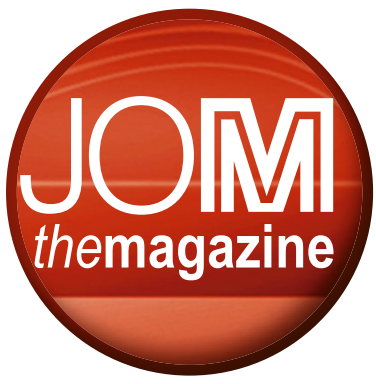

\section{TMS Board of Directors \\ David H. DeYoung \\ President \\ Director, Research \\ and Development, \\ Alcoa}

\section{Stanley M. Howard \\ Past President \\ Professor Emeritus, \\ South Dakota School of \\ Mines \& Technology \\ Kevin J. Hemker \\ Vice President \\ Alonzo G. Decker Chair in \\ Mechanical Engineering,}

Johns Hopkins University

Joy H. Forsmark

Financial Planning Officer

Technical Expert,

Light Cast Metals,

Ford Motor Company

Amy J. Clarke

Director, Membership \&

Student Development

Associate Professor,

Colorado School of Mines

\section{Michele V. Manuel}

Director, Content

Development \&

Dissemination

Professor,

University of Florida

Alan A. Luo

Director/Chair

Light Metals Division

Professor and Director,

Light Metals and

Manufacturing

Research Laboratory,

The Ohio State University

\title{
Staying Connected as a TMS Member
}

\author{
David H. DeYoung, 2017 TMS President
}

\section{TMS board motions, minutes, and musings}

This regular JOM feature offers news and perspectives on TMS governance, as well as Board of Directors activities, priorities, and decisions. To find out how you can become involved in these initiatives, contact James J. Robinson, TMS Executive Director, at robinson@tms.org.

What is the value of your TMS membership? Indirectly, we ask our

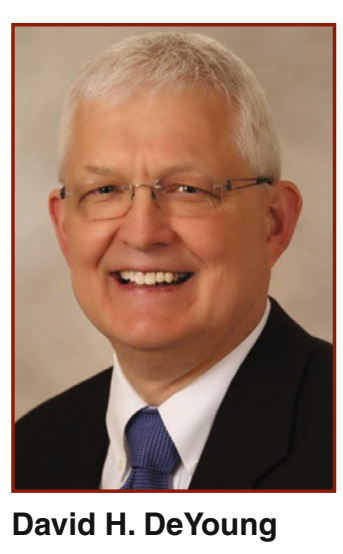

members to

consider this

question each

time we ask them

to renew for the

coming year.

I value my membership in

TMS because it allows us all to stay connected with the leading technologists in our field, either

directly through face-to-face interactions at TMS meetings and short courses or indirectly through technical articles in TMS journals and conference proceedings. And, staying connected enables us, as a community, to continue to incorporate the latest developments into our work.

In 2018, we will again have ample opportunity to connect with minerals, metals, and materials scientists and engineers at events like the TMS 2018 Annual Meeting \& Exhibition (TMS2018) in Phoenix, Arizona, March 11-15. Like previous installments, TMS2018 will foster connections among those from industry, academia, and government laboratories; connections between students and working professionals; and connections among professionals from around the world. A special TMS2018 co-located meeting that will help members gain further international perspective on their work is the 2nd International Conference on Computational Design and Simulation of Materials (CDSM 2018), co-organized by TMS and the Chinese Society for Metals.

New TMS opportunities to advance our professional community in 2018 include
Extraction 2018, which will debut August 26-29, 2018 in Ottawa, Canada. Designed to bring together the world's extractive metallurgy community in a single event, Extraction 2018 will incorporate several of the field's recurring symposia with programming and member participation from TMS, the Metallurgy and Materials Society (MetSoc) of the Canadian Institute of Mining, Metallurgy and Petroleum (CIM), and the Society for Mining, Metallurgy \& Exploration (SME).

We are also extremely excited to offer Additive Manufacturing Benchmarks 2018, set for June 18-21 at the National Institute of Standards and Technology (NIST) headquarters in Maryland. This unique program gives a platform to additive manufacturing experts to share their current work and to present results from simulations tested against rigorous, highly controlled additive manufacturing benchmark test data.

We'll also continue the important work of the Diversity in the Minerals, Metals, and Materials Professions (DMMM) series. The third installment (DMMM3) will be held July 23-24, 2018 in Santa Barbara, California.

I believe the issues we explore in our DMMM conference series are critical to the progress of our field. My four decades of experience in engineering have taught me that diversity in perspective leads to diversity in thought, and diversity in thought leads to solutions to problems. I can't count the number of times that interactions with someone having a different perspective than my own has led to the solution to a problem.

Other important recurring meetings set for 2018 at press time include 2018 Superalloy 718 and Derivatives: Energy, Aerospace, and Industrial Applications 


\section{TMS Board of Directors}

\section{Chester Van Tyne \\ Director, Professional \\ Development \\ FIERF Professor, \\ Colorado School of Mines}

Corbett C. Battaile

Director/Chair

Materials Processing \&

Manufacturing Division

Principal Member of

Technical Staff, Sandia

National Laboratory

\section{John Howarter}

Director, Public \&

Governmental Affairs

Assistant Professor,

Purdue University

\section{Ellen K. Cerreta \\ Director/Chair \\ Structural Materials \\ Division \\ Group Leader, \\ Los Alamos National \\ Laboratory}

\section{Srinivas Chada}

Director, Programming

Senior Principal Engineer,

Stryker

\section{Raymundo Arroyave \\ Director/Chair \\ Functional Materials \\ Division \\ Associate Professor, \\ Texas A\&M University}

\section{Cynthia Belt}

Director/Chair

Extraction \& Processing

Division

Metals Energy

Management LLC

James J. Robinson

Secretary

TMS Executive Director
(June 3-6, Pittsburgh, Pennsylvania) and the 4th International Congress on 3D Materials Science (June 10-13, Helsingør, Denmark.) TMS is also developing a number of other events as well, including the return of our popular series of courses for the aluminum industry.

Your membership will allow you to register for select TMS meetings and events at a discounted member rate; I hope to see you there!

Attending meetings, however, isn't the only way to stay connected to your community. I hope that you also value the latest research delivered to you every month in TMS journals. As members, we have access to an expansive and valuable collection of technical articles, through print and electronic subscriptions to $J O M$, as well as electronic subscriptions to Integrating Materials and Manufacturing Innovation, Journal of Electronic Materials, Journal of Sustainable Metallurgy, and Metallurgical and Materials Transactions $A$ and $B$. Both the number of papers published in our journals and the impact factors of those journals continue to rise.

However, we recognize that, as we print more technical papers in each issue of $J O M$, a print subscription to the journal takes up significantly more space on our members' bookshelves. So this year, we are asking you to indicate your preference in receiving $J O M$ every month - either in both print and electronic formats or just electronic-only distribution.

The value of TMS membership also includes the chance to influence the future of the profession and to build broad networks in the communities where we work by joining technical committees populated by our colleagues. Serving on our technical and administrative committees is a great way to interact with other professionals and provides great leadership training. TMS was developing the technical content of our conferences by "crowdsourcing" through our bottomup committees long before crowdsourcing became a social phenomenon.

Whether it is conference attendance, journal access, or the overall sense of camaraderie with your community that keeps you coming back to TMS, I encourage you to take two simple steps today to invest in the future of your career. First, renew your TMS membership for 2018 at members.tms.org. Second, I strongly suggest joining the TMS technical committee that best aligns with your technical interests. Learn how at www.tms .org/volunteer.

I hope that you value, as much as I do, the connections to our community that TMS provides. And, I look forward to all of the contributions you'll make to our society in the year ahead.

\section{Update Your Profile and Keywords with TMS}

When you log in to the "Access Member Benefits" section of the TMS website to renew your membership, please take a few minutes to update your profile with the society to make sure that we have your most current contact information. Also, TMS has recently changed its technical interest area keywords, so please review your keyword selections. When we know the technology areas that interest you most, we can alert you to activities

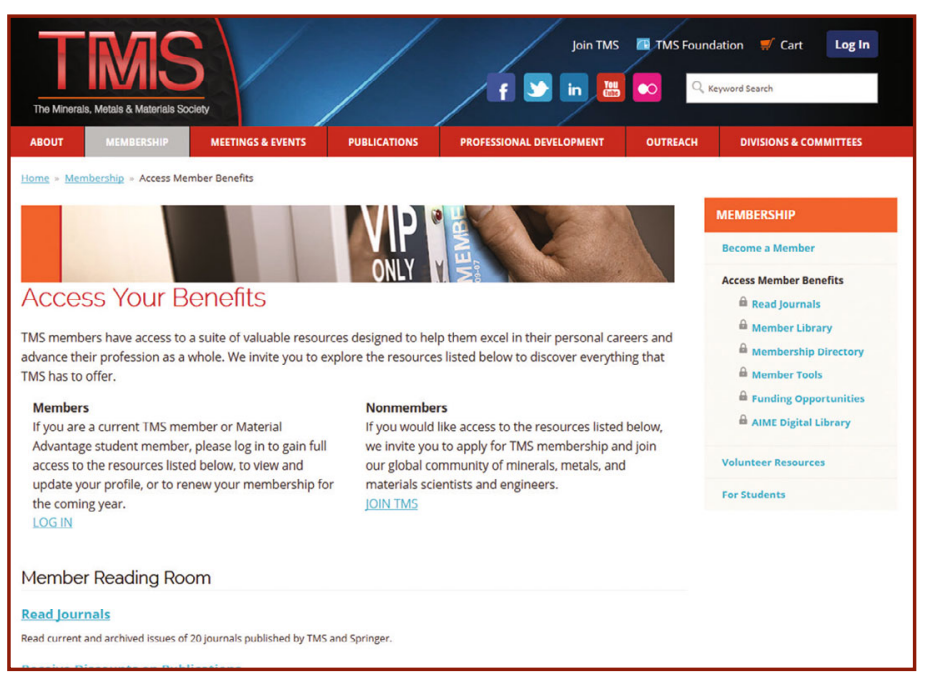

happening in your specific area. Log in to members.tms.org to update your information. 